\title{
Production Methods of Laminated Al Alloy Composites
}

\author{
Yalun Sun* \\ Beijing Institute of Technology, China
}

*Corresponding author: Yalun Sun, Beijing Institute of Technology, China.

Received Date: July 05, 2019

Published Date: July 19, 2019

\begin{abstract}
$\mathrm{Al}$ alloy is widely used because of its versatility. Al can alloy with a variety of elements and produce materials with different properties. Efforts have been made to join two kinds of Al alloys together. This combination can take both materials' advantages and may even have superior property over both starting materials. Researches showed that the combination of certain alloys can help improve the corresponding property, such as mechanical strength and thermal/electrical conductivity. Another practical use is to reduce the overall price while remaining acceptable properties. In this paper, 6 different methods for producing laminated metal composites (LMCs) were briefly reviewed.
\end{abstract}

Keywords: Al alloy; laminated metal composites; Bonding

\section{Introduction}

Aluminium (Al) is the third mostabundant element, after oxygen and silicon, in the Earth's crust. It is remarkably light its density is only around $1 / 3$ that of $\mathrm{Fe}$, giving it advantage in applications in vehicles and aircrafts/spacecrafts. Although $\mathrm{Al}$ is highly reductive, it can resist environmental oxidation and corrosion due to a dense layer of $\mathrm{Al}_{2} \mathrm{O}_{3}$ which naturally forms on the surface. The oxide layer is only a few micrometers thick, so it does not have a huge influence on the purity, meanwhile, it is highly effective in protecting the inner Al from contact with the oxidizer in the environment [1]. $\mathrm{Al}$ is almost always alloyed to improve the mechanical properties. Even the industrial pure $\mathrm{Al}$ can be considered as an alloy with $\mathrm{Fe}$ and $\mathrm{Si}$. Al alloys can be divided into two major categories: casting compositions and wrought compositions [2]. While the Al melts during casting, wrought alloy remains solid during the processing. All kinds of efforts have been made to improve the mechanical strength of the alloy. One way to improve the mechanical properties is to alter the microstructure of the alloy. Research shows that the crack growth in ultrafine and coarse grain $\mathrm{Al}$ alloys will be different. It is possible that the grain boundaries in the ultrafine grain $\mathrm{Al}$ alloy can capture the crack and hinder its further growth [3]. Another way is to dope the alloy. Researches show that doping with Nb helps improve the thermal stability [4] while doping with $\mathrm{SiC}, \mathrm{Al}_{2} \mathrm{O}_{3}$, and $\mathrm{MgO}$ can improve the alloy's yield strength, ultimate tensile strength (UTS), hardness, and decreased elongation (ductility) [5-7]. Despite the promising results, the improvement of performance is always accompanied with an increase in price. However, producing $\mathrm{Al}$ alloy
LMCs may help with obtaining both reasonable price and desired properties.

\section{Methods for Joining Alloys}

A variety of methods have been developed to join different metals and they have their own strength and limitations. The main idea of the joining methods is to form a transaction area at the interface. The produced composite can be a good combination of different properties [8,9].

\section{Roll bonding}

Roll welding is a type of pressure welding or solid-state welding techniques where bonding is established by joint plastic deformation of the metals to be bonded [10]. It is the establishment of an atom-to-atom bond between two pieces to be joined through intimate contact between contaminant free areas [11]. In roll bonding, a threshold degree of deformation has to be reached to achieve the bonding. Roll bonding can be split into warm/hot roll bonding and cold roll bonding, and the difference lies in the operation temperature. While hot roll bonding may require 700$1000^{\circ} \mathrm{C}$, cold roll bonding can happen in room temperature [12]. Parameters including the amount of deformation [13-18], the metal under consideration [19], the temperature of welding [20$22]$, etc. will influence the properties of the obtained material. All these parameters will have similar influence on samples prepared by similar process. The manufacture procedure of roll bonding has 
been well established, which brings down the price. However, roll bonding, especially cold roll bonding, requires high purity of the metal's surface [23].

\section{Diffusion bonding}

Diffusion bonding is useful in joining metals that has initial oxide layer and/or forms brittle intermetallic in the bonding region, because diffusion bonding requires more smoothness than the composition of the bonding surfaces. The point of diffusion bonding is to provide a greater contact area, in order to increase the atomic diffusion paths [24]. Since no surface is absolutely flat, the workpiece to be bonded should be plastically deformed locally through an applied stress. If the flow stress of the material is high, the applied stress will not be enough to cause local plastic deformation of this material. Then many voids and pores will remain at the interface after diffusion bonding. In this case, a good joint cannot be achieved, and the bonding quality will be degraded. Although higher pressure or longer heating time could improve the bonding effect for these high strength materials [25-27], the manufacturing cost will be increased $[24,28]$.

The predominant process parameters in diffusion bonding process are bonding temperature, bonding pressure and holding time [29-33].

\section{Explosion welding}

Explosion welding (EXW) is a solid-state metal-joining process that uses explosive to create an electron-sharing metallurgical bond between two metal components. It has successful joint all kinds materials [34-40]. Although the explosive detonation generates considerable heat, there is not time for heat transfer to the component metals; therefore, there is no appreciable temperature increase in the metals [41]. To achieve a good weld result, some conditions need to be met, which is called as a weldability window or criteria. A weldability criterion based on the collision point velocity $(\mathrm{Vc})$ and on the collision angle $(\beta)$ is the most used today [42]. The advantage of EXW is that is can join different kinds of materials. It also has no restrictions on the size or surface condition of the material because the detonation wave can help remove the oxides or contaminations on the surface. However, because it is based on explosion, the obtained materials always need some post process. Also, this method performs better on thick plates.

\section{Friction stir welding}

Friction stir welding (FSW) uses simple and special designed tool with a shoulder and a pin (or probe) which causes thermomechanical action for joining the materials [43]. It is efficient in joining soft and low melting point alloys; therefore, a large amount of $\mathrm{Al}$ and $\mathrm{Mg}$ alloys have been cladded using this method [44-49]. FSW is suitable for some critical applications such as welding of high strength pipelines, but the width and depth of the alloys that can be joint are restricted by the size of the pin.

\section{Hot pressing}

Hot pressing has been applied on bonding $\mathrm{Mg}$ and $\mathrm{Al}[50,51]$. In this case, powdery solder is needed. In the mentioned reference,
$\mathrm{Mg}-\mathrm{Al}$ eutectic alloy was used as the solder for joining $\mathrm{Mg}$ and $\mathrm{Al}$, and it was operated under $400-500^{\circ} \mathrm{C}$. This method used to require a duration of high temperature and pressure of $2 \mathrm{~h}$ [50], but the more recent modification of this method shortened the duration to no more than 1 min [51].

\section{Direct-chill casting}

Direct-chill (DC) casting is the major production route for wrought aluminium and magnesium alloys that are later deformed (rolled, extruded, forged) to the final products [52,53]. Using a double-stream-pouring in direct-chill casting gives the possibility of producing a bi-metal or sandwich structured slabs [54-56].

\section{Conclusion}

In conclusion, the above-mentioned methods are suitable for joining two alloy slabs. However, problems such as the oxidation during production may result in a weak bonding between different components. Therefore, further improvements are still in need to satisfy the requirements for $\mathrm{Al}$ alloy LMCs.

\section{Acknowledgement}

None.

\section{Conflict of Interest}

No conflict of interest.

\section{References}

1. Davis Joseph R (1999) Corrosion of aluminum and aluminum alloys. Asm International.

2. Davis Joseph R (1993) Aluminum and aluminum alloys. ASM international.

3. Meng Li, Anchal G, Véronique D, Nicolas R, Jean-Philippe C (2019) Ultrafine versus coarse grained Al 5083 alloys: From low-cycle to veryhigh-cycle fatigue. International Journal of Fatigue 121: 84-97.

4. Galano M, Fernando A, Ian S, Cantor B (2008) Effect of $\mathrm{Nb}$ on nanoquasicrystalline Al-based alloys. Philosophical Magazine Letters 88(4): 269-278.

5. Kheder ARI, Marahleh GS, DMK Al-Jamea (2011) Strengthening of Aluminum by $\mathrm{SiC}, \mathrm{Al} 2 \mathrm{O} 3$ and MgO. Jordan Journal of Mechanical \& Industrial Engineering 5(6).

6. Su H, Wenli G, Zhaohui F, Zheng L (2012) Processing, microstructure and tensile properties of nano sized $\mathrm{Al}_{2} \mathrm{O}_{3}$ particle reinforced aluminum matrix composites. Materials \& Design 36: 590-596.

7. Devaraju A, Kumar A, Kumaraswamy A, Kotiveerachari B (2013) Influence of reinforcements $\left(\mathrm{SiC}\right.$ and $\mathrm{Al}_{2} \mathrm{O}_{3}$ ) and rotational speed on wear and mechanical properties of aluminum alloy 6061-T6 based surface hybrid composites produced via friction stir processing. Materials \& Design 51: 331-341.

8. Kim, Jeong I, Chung Gil K, Hyok-Chon K (1999) Extrusion process analysis of $\mathrm{Al} / \mathrm{Cu}$ clad composite materials by finite element method. J Kor Soci Comp Mater 12(5).

9. Avitzur B, Wu R, Talbert S, Chou YT (1982) Criterion for the prevention of core fracture during extrusion of bimetal rods. journal of engineering for industry 104(3): 293-304.

10. Eizadjou M, H Danesh M, Janghorban K (2009) Mechanism of warm and cold roll bonding of aluminum alloy strips. Materials \& Design 30(10): 4156-4161.

11. Madaah-Hosseini HR, Kokabi AH (2012) Cold roll bonding of 5754-aluminum strips. Materials Science and Engineering: A 335(1-2): 186-190. 
12. Hu, Lei (2011) Research and development of $\mathrm{Cu} / \mathrm{Mo} / \mathrm{Cu}$ laminated composite material. Powder Metallurgy Technology.

13. Le HR, Sutcliffe MPF, Wang PZ, Burstein GT (2004) Surface oxide fracture in cold aluminium rolling. Acta Materialia 52(4): 911-920.

14. Zhang, Wenqi, Niels Bay (1997) Cold welding-experimental investigation of the surface preparation methods. Welding journal 76(8): 326s-330s.

15.Zhang, Wenqi, Niels Bay (1997)Cold welding-theoretical modeling of the weld formation. Welding Journal-Including Welding Research Supplement 76(10): 477s.

16. Furmidge JE, Howd D, Tylecote RF (1958) The influence of surface films on the pressure welding of metals. British Welding Jour 5(1): 21-38.

17. Milner DR, Vaidyanath LR (1960) Significance of surface preparation in cold pressure welding. Met Constr Br Weld J 7: 1-6.

18. Sherwood WC, Milner DR (1969) The effect of vacuum machining on the cold welding of some metals. J Inst Metals 97(1): 1-5.

19. Lukaschkin ND, Borissow AP, Erlikh AI (1997) The system analysis of metal forming technique in welding processes. Journal of materials processing technology 66(1-3): 264-269.

20. Yahiro, Akihito (1991) Development of nonferrous clad plate and sheet by warm rolling with different temperature of materials. ISIJ international 31(6): 647-654.

21. An J, Y Lu, DW Xu, YB Liu, DR Sun, et al. (2001) Hot-roll bonding of Al$\mathrm{Pb}$ bearing alloy strips and hot dip aluminized steel sheets. Journal of materials engineering and performance 10(2): 131-135.

22. Peng XK, Greg H, Wing Y (1999) Yeung Effect of rolling temperature on interface and bond strength development of roll bonded copper/ aluminium metal laminates. Journal of materials science 34(2): 277281.

23. Kim Su-H, Hyoung-Wook K, Kwangjun E, Joo-Hee K, Jae-Hyung C (2012) Effect of wire brushing on warm roll bonding of $6 \mathrm{XXX} / 5 \mathrm{XXX} / 6 \mathrm{XXX}$ aluminum alloy clad sheets. Materials \& Design 35: 290-295.

24. Yeh MS, Chuang TH (1995) Low-pressure diffusion bonding of SAE 316 stainless steel by inserting a superplastic interlayer. Scripta metallurgica et materialia 33(8): 1277-1281.

25. Garmong G, NE Paton, Argon AS (1975) Attainment of full interfacial contact during diffusion bonding. Metallurgical Transactions A 6(6): 1269-1279.

26. Wisbey A, Partridge PG (1993) Diffusion bonding of high temperature titanium alloy IMI 834. Materials science and technology 9(5): 441-446.

27. Deqing, Wang, Shi Ziyuan, Qi Ruobin (2007) Cladding of stainless steel on aluminum and carbon steel by interlayer diffusion bonding. Scripta materialia 56(5): 369-372.

28. Mahendran G, Balasubramanian V, Senthilvelan T (2009) Developing diffusion bonding windows for joining AZ31B magnesium-AA2024 aluminium alloys. Materials \& Design 30(4): 1240-1244.

29. He P, Feng JC, Zhang BG, Qian YY (2002) Microstructure and strength of diffusion-bonded joints of TiAl base alloy to steel. Materials Characterization 48(5: 401-406.

30. Peng L, Li Y, Geng H, Wang J (2006) Investigation of interfacial structure of $\mathrm{Mg} / \mathrm{Al}$ vacuum diffusion-bonded joint. Vacuum 80(5): 395-399.

31. Li Y, Peng L, Juan W, Haijun M (2007) XRD and SEM analysis near the diffusion bonding interface of $\mathrm{Mg} / \mathrm{Al}$ dissimilar materials. Vacuum 82(1): 15-19.

32. Peng L, Li Y, Geng H, Wang J (2005) A study of phase constitution near the interface of $\mathrm{Mg} / \mathrm{Al}$ vacuum diffusion bonding. Materials Letters 59(16): 2001-2005.

33. Huang Y (1998) Diffusion bonding of hot rolled 7075 aluminium alloy. Materials science and technology 14(5): 405-410.

34. Linse VD, Temple PI (1991) Explosion welding, AWS Welding Handbook - Volume 2 - Welding Processes, American Welding Society, USA, pp: 765-781
35. Carvalho GHSFL (2018) Explosive welding of aluminium to stainless steel. Journal of Materials Processing Technology 262: 340-349.

36. Mendes R (2012) Non ideal detonation of emulsion explosives mixed with metal particles. AIP Conference Proceedings. 1426(1).

37. Mendes R (2014) Differences between the detonation behavior of emulsion explosives sensitized with glass or with polymeric microballoons. Journal of Physics: Conference Series. 500(5) IOP Publishing, Uk.

38. Wronka B (2010) Testing of explosive welding and welded joints. The microstructure of explosive welded joints and their mechanical properties. Journal of materials science 45(13): 3465-3469.

39. Gulenc B (2008) Investigation of interface properties and weldability of aluminum and copper plates by explosive welding method. Materials \& Design 29(1): 275-278

40. Ashani JZ, SM Bagheri (2009) Explosive scarf welding of aluminum to copper plates and their interface properties. Materialwissenschaft und Werkstofftechnik 40(9): 690-698.

41. Findik, Fehim (2011) Recent developments in explosive welding. Materials \& Design 32(3): 1081-1093.

42. Ribeiro JB, Mendes R, Loureiro A (2014) Review of the weldability window concept and equations for explosive welding. Journal of Physics: Conference Series, IOP Publishing, UK, 500(5).

43. Rai R (2011) Friction stir welding tools. Science and Technology of welding and Joining 16(4): 325-342.

44. Rhodes CG (1997) Effects of friction stir welding on microstructure of 7075 aluminum. Scripta materialia 36(1).

45. Sato, Yutaka S (1999) Microstructural evolution of 6063 aluminum during friction-stir welding. Metallurgical and Materials Transactions A 30(9): 2429-2437.

46. Benavides Sa (1998) Low-temperature friction-stir welding of 2024 aluminum.

47. Watanabe, Takehiko, Hirofumi T, Atsushi Y (2006) Joining of aluminum alloy to steel by friction stir welding. Journal of Materials Processing Technology 178(1-3): 342-349.

48. Esparza JA (2002) Friction-stir welding of magnesium alloy AZ31B. Journal of materials science letters 21(12): 917-920.

49. Kwon YJ, Ichinori S, Naobumi S (2008) Dissimilar friction stir welding between magnesium and aluminum alloys. Materials Letters 62(23): 3827-3829

50. Li, Xian R (2009) Bonding of Mg and Al with Mg-Al eutectic alloy and its application in aluminum coating on magnesium. Journal of Alloys and Compounds 471(1-2): 408-411.

51. Zhu B, Wei L, Xianrong Li (2011)Interfacial microstructure, bonding strength and fracture of magnesium-aluminum laminated composite plates fabricated by direct hot pressing. Materials Science and Engineering: A 528(21): 6584-6588.

52. Grandfield, John, Dmitry G, Eskin, Ian B (2013)Direct-chill casting of light alloys: science and technology. John Wiley \& Sons.

53. Hamdi M, Asbjørn M, Christophe LM (2002) Two-phase modeling directed toward hot tearing formation in aluminum direct chill casting. Metallurgical and materials transactions a 33(7): 2081-2093.

54. Li Yu, Fei J, Chen W, Zhang W, Shao M (2002) Preparation of 2024/3003 gradient materials by semi-continuous casting using double-streampouring technique. Journal of Central South University of Technology 9(4): 229-234

55. Zhang, Wei W (2007) Effect of plastic deformation on microstructure and hardness of AlSi/Al gradient composites. Transactions of Nonferrous Metals Society of China 17(6): 1186-1193.

56. Xiaoping Z (2008) Preparation of 7075/6009 Gradient Aluminum Matrix Composites by Semi-continuous Casting [J]. Special Casting \& Nonferrous Alloys. 